\title{
DIREITOS FUNDAMENTAIS E O CONSUMO: A BUSCA DE PROTEÇÃO SOCIAL E AMBIENTAL
}

\section{THE FUNDAMENTAL RIGHTS OF THIRD GENERATION AND CONSUMPTION: THE SEARCH FOR SOCIAL AND ENVIRONMENTAL PROTECTION}

\author{
Cleide Calgaro ${ }^{1}$ \\ César Augusto Cichelero ${ }^{2}$ \\ Ramon da Silva Sandi ${ }^{3}$
}

Resumo: $O$ presente trabalho analisa os direitos fundamentais de terceira geração a partir do consumo e meio ambiente, inserindo-os na concepção de direitos fraternos e solidários na sociedade globalizada. Inicialmente se faz uma genealogia dos Direitos Fundamentais e se analisa seus principais conceitos ao longo do tempo. A seguir se estuda o consumo como supressão, onde se verifica as contrariedades que a sociedade de consumo pode apresentar, inclusive o consumocentrismo quando relacionada aos direitos de terceira geração. Se apresenta a partir desta seção é de que não acontece uma globalização do direito ao consumo, mas uma globalização da proteção de consumidores atomizados. Após se observa o consumo como forma de realização, onde se verifica que os Direitos Fundamentais de terceira geração, antes de serem naturalmente suprimidos pela prática consumerista, podem ser, de certo modo, efetivados através da cidadania presente no consumo, possibilitando uma base integrativa e a sua eficácia entre a sociedade e o direito. $O$ método utilizado é o analítico. Conclui-se que há alternativas que permitem a efetivação desses direitos de terceira geração na sociedade de consumocentrista hodierna.

Palavras-chave: Direitos fundamentais de terceira geração. Consumo. Meio ambiente. Socioambientalismo.

\begin{abstract}
This paper analyzes the fundamental rights of third generation from the consumption and the environment, inserting them in the conception of fraternal and solidarity rights in the globalized society. First, it's made a genealogy of Fundamental Rights and is analyzed its main concepts over the time. Next, the consumption is studied as a suppression, where we can see the setbacks that the consumer society presents, including hyper-consumerism when related to third generation rights. It is presented that there is no globalization of the right to consumption, but a globalization of the protection of atomized consumers. After, the consumption is observed as an implementation of the rights, it is verified that the fundamental rights of third generation, before being naturally suppressed by the consumerist practice, can be, to a certain extent, effected through the citizenship present in the consumption, allowing an integrative and its effectiveness between society and law. It's used the analytical method. We concluded that there are alternatives that allow the realization of these third generation rights in today's hyper-consumerism society.
\end{abstract}

Keywords: Fundamental rights of third generation. Consumption. Environment. Socio-environmentalism.

Recebido em 11 de junho de 2018 Avaliado em 20 de agosto de 2018 (AVALIADOR A) Avaliado em 13 de novembro de 2018 (AVALIADOR B)

Avaliado em 26 de junho de 2019 (AVALIADOR C) Aceito em 27 de junho de 2019

\footnotetext{
1 Doutora em Ciências Sociais pela Universidade do Vale do Rio dos Sinos; Professora e pesquisadora no Programa de Pós-Graduação (Mestrado e Doutorado) e na Graduação em Direito da Universidade de Caxias do Sul; Rua Francisco Getúlio Vargas, 1130, 95070-560, Caxias do Sul, Brasil; https//orcid.org/0000-0002-1840-9598; ccalgaro1@hotmail.com

2 Graduado em Direito pela Universidade de Caxias do Sul; mestrando em Direito na Universidade de Caxias do Sul; http:// orcid.org/0000-0002-1454-4231; cesar.cichelero@gmail.com

3 Bacharel em Filosofia e em Direito pela Universidade de Caxias do Sul; mestrando em Direito pelo Programa de Pós-Graduação em Direito da Pontifícia Universidade Católica do Rio Grande do Sul; https://orcid.org/0000-0003-1918-1844; rsilvasandi@gmail.com
} 


\section{Considerações iniciais}

O presente trabalho visa fazer uma análise dos direitos fundamentais de terceira geração trabalhando como o consumo se insere nessa nova concepção de direitos fraternos e solidários e a preocupação com o meio ambiente na sociedade globalizada.

Inicialmente se faz uma genealogia dos Direitos Fundamentais e se analisa seus principais conceitos ao longo do tempo, onde esses direitos de solidariedade e fraternidade estão inseridos no preceito constitucional de 1988, garantindo os direitos, no caso em tela, difusos sendo eles o direito do consumidor e o meio ambiente.

A seguir se estuda o consumo, deste modo, para efeitos deste artigo, deve-se ter em mente o consumo como o "conjunto de processos socioculturais em que se realizam a apropriação e os usos dos produtos." (CANCLINI, 2006, p. 60). Visto que "consumir é participar de um cenário de disputas por aquilo que a sociedade produz e pelos modos de usá-lo." (CANCLINI, 2006, p. 62). Para isso se vislumbra o consumo como supressão, onde se verifica as contrariedades que a sociedade de consumo pode apresentar, inclusive o consumocentrismo quando relacionada aos direitos de terceira geração. Se apresenta a partir desta seção é de que não acontece uma globalização do direito ao consumo, mas uma globalização da proteção de consumidores atomizados.

$\mathrm{Na}$ seção seguinte se indaga o consumo como forma de realização, onde se verifica que os Direitos Fundamentais de terceira geração, antes de serem naturalmente suprimidos pela prática consumerista, podem ser, de certo modo, efetivados através da cidadania presente no consumo e de algumas alternativas propostas, possibilitando uma base integrativa e a sua eficácia entre a sociedade e o direito.

O método utilizado é o analítico tendo como base estudos bibliográficos. Conclui-se que existem alternativas que podem efetivar os direitos de terceira geração - solidariedade e fraternidadena sociedade de consumo atual, os quais serão expostos a guisa de conclusão.

\section{Conceito e genealogia dos Direitos Fundamentais}

Em sua genealogia, a história dos direitos fundamentais é a história dos direitos subjetivos dos cidadãos perante o poder do governante e do Estado, assim como a proteção desses direitos contra a própria vontade geral do povo representada pelo poder legislativo. Seguindo Canotilho (1998, p. 347), os "direitos fundamentais são-no, enquanto tais, na medida em que encontram reconhecimento nas constituições e deste reconhecimento se derivam consequências jurídicas." Essas consequências jurídicas consubstanciaram-se em vinculação dos poderes e nas ações estatais para que houvesse conformidade axiológica e operacional com os princípios e fundamentos que as cartas Constitucionais foram, ao longo do tempo, catalogando através da Assembleia Constituinte de cada Estado-nação. Isso posto, é mister recordar, pois, considerando o constitucionalismo como 
lei positiva de determinado Estado, que, as gerações de direitos que serão expostas nesse texto, principalmente a terceira geração, refere-se à dimensão de direitos codificadas nas Leis Fundamentais. Desse modo, mesmo que haja nítida influência, estar-se-á perante a tese de que não necessariamente os direitos fundamentais advenham estritamente da dignidade substanciada nos direitos humanos, a partir de um caráter supranacional (SARLET, 2018, p. 307).

Os Direitos Fundamentais considerados de primeira geração ${ }^{4}$ referem-se, ao dever do Estado de ação negativa. Já em 1215, contra os poderes do rei inglês, João Sem-Terra, e dos writs, ${ }^{5}$ os senhores feudais, através da Magna Carta, delimitaram a jurisdição real sobre barões e vassalos (GILISSEN, 2003, p. 210). Após esse período, ainda na Inglaterra, em 1689, tem-se a Revolução Gloriosa, com a supremacia do parlamento numa monarquia constitucional. Nesses fatos, planta-se a base para o poder de resistência, apesar de estar muito delimitado a uma parte da hierarquia social concernentes aos barões e nobres. Como afirma Schmitt (1993, p. 295),

on a souvent cite comme première déclaration de droits fondamentaux la Magna carta 1215, lês actes d'habeas corpus de 1679 (garantie contre lês arrestations arbitraires et droit à une audition par um juge) et Le Bill of Rights de 1688. Ce sont em realité des reglementations par pacte ou par loi des droits des barons ou des citoyens anglais qui ont revêtu au cours d'une évolution evolution progressive le caractere de príncipes modernes, mais sans avoir Le sens originel de droits fonsamentaux. ${ }^{6}$

A partir da concretização dos direitos baseados em princípios nitidamente expostos pelo Iluminismo, constatam-se suas influências às revoluções Americana e Francesa. Tem-se na primeira a edição da Constituição Federal de 1787, influenciada pelas declarações de direitos dos Estados da Virgínia (1776) e da Pensilvânia (1776). Os direitos fundamentais descritos em tais declarações são a liberdade em geral; liberdade religiosa e de crença; direito de resistência; propriedade privada e segurança (SCHMITT, 1993, p. 295). O que é importante ter presente nos ideais americanos é que esses, diferentemente da Inglaterra, não tiveram apenas

por finalidade limitar o poder do rei, [para] proteger o indivíduo contra a arbitrariedade do rei e firmar as supremacia do Parlamento. As Declarações de Direitos, iniciadas com a da Virgínia, importam em limitações do poder estatal,

\footnotetext{
4 O uso termo "geração" de direitos Fundamentais gera muitas críticas, pois ao invés de possuir conotação de suprassunção conceitual, expõe certo sentido de supressão. Como afirma Sarlet (2006, p. 54) "Com efeito, não há como negar que o reconhecimento progressivo de novos direitos fundamentais tem o caráter de um processo cumulativo, de complementaridade, e não de alternância, de tal sorte que o uso da expressão 'gerações' pode ensejar a falsa impressão da substituição gradativa de uma geração por outra." Entretanto, como nesse artigo trabalhar-se-á especificamente a terceira geração ou dimensão dos Direitos Fundamentais, tendo por base autores como Paulo Bonavides e Karel Vasak, prefere-se, a partir da terminologia utilizada por esses autores, dispor do termo "Gerações", sem esquecer, é claro, a reiteração feita pelo professor Sarlet de que possuem caráter de complementaridade e não de alternância.

5 Os writs eram o aceite para um pedido requerido por alguém do povo, expedido pó um colaborador do rei. Essa era uma ordem ao réu para satisfazer a queixa do autor do pedido (GILISSEN, 2003, p. 210).

6 Temos costume de citar como a primeira declaração de direitos fundamentais a Carta Magna de 1215, os atos de habeas corpus de 1679 (garantia contra as prisões arbitrárias e direito a uma audição por um juiz) e o Bill of Rights de 1688. São em realidade regras para pacto ou por lei dos direitos dos barões ou dos cidadãos ingleses que assumiram uma revolução progressiva de caráter de princípios modernos, mas sem haver o sentido original dos direitos fundamentais (tradução nossa).
} 
como tal, inspiradas na crença na existência de direitos naturais e imprescritíveis do homem. (SILVA, 2014, p. 156).

Mas é com a Revolução Francesa que esses ideais de direitos perpassam as instituições e aos cidadãos dos burgos de tal país. Antes da Revolução, o próprio Rei Luís XIV afirmava que era a total representação do Estado (L'etat c'est moi) e havia os juristas que procuravam fundamentar em sua seara "a onipotência do monarca - os direitos do rei - diante das resistências que este encontrava no exercício corrente do poder." (LAQUIÈZE, 2006, p. 339). Contra esse poder arbitrário, a França pressupõe direitos, tal como os americanos, de propriedade, liberdade, segurança e de resistência. Contudo, não garante a liberdade religiosa, nem de associação.

Com o desenvolver da civilização, principalmente a partir de aspectos socioeconômicos, nota-se a necessidade de uma tutela prestativa do Estado que não se limite a garantir as liberdades pessoais, mas que ao prestar uma tutela social por meio da vinculação jurídica constitucional, os próprios direitos à liberdade e propriedade estariam preservados. É importante recordar que a passagem a uma tutela prestativa do Estado se deve, principalmente, à industrialização e aos graves problemas socioeconômicos dela advindos,

gerando amplos movimentos reivindicatórios e o reconhecimento progressivo de direitos, atribuindo ao estado comportamento ativo na realização da justiça social [...] revelando uma transição das liberdades formais abstratas para as liberdades materiais concretas, utilizando-se a formulação preferida da doutrina francesa. (SARLET, 2018, p. 319).

A partir da concretização desse Estado Social, chega-se ao momento, entretanto, com a globalização do comércio e da própria convivência humana, que a tutela dos Direitos Fundamentais não permite que seja vinculada somente à prestação Estatal, mas necessita que, a partir das relações entre os particulares, possa haver a existência da promoção desses direitos. Com maestria, afirma Bonavides (2014, p. 583-584, grifo do autor) que

Com efeito, um novo pólo jurídico de alforria do homem se acrescenta historicamente aos da liberdade e da igualdade. Dotados de altíssimo teor de humanismo e universalidade, os direitos de terceira geração tendem a cristalizarse no fim do século XX enquanto direitos que não se destinam especificamente à proteção dos interesses de um indivíduo, de um grupo ou de um determinado Estado. Têm primeiro por destinatário o gênero humano mesmo, num momento expressivo de sua afirmação como valor supremo em termos de existencialidade concreta. Emergiram eles da reflexão sobre temas referentes ao desenvolvimento à paz, ao meio ambiente, à comunicação e ao patrimônio comum da humanidade.

Com isso, tem-se que a fraternidade (ou solidariedade) que passa a ser elemento fundamental na compreensão de Estado Democrático de Direito, figura-se num maior direito de participação do cidadão à tutela de direitos como o meio ambiente e à paz. Essa compreensão da fraternidade 
humana presente na terceira geração de direitos tem como um dos principais idealizadores teóricos o professor Karel Vasak. Ao justificar sua adesão à compreensão desses direitos, o autor afirma que

n'y-a-t-il pás, ne devrait-il pás y avoir, des droits de l'homme secretes par l'evidente fraternité des hommes et par leur indispensable solidarité, droits qui uniraient lês hommes dans um monde fini dont le temps a comencé depuis longtemps dejà? Tel est le sens de nouveaux droits de l'homme de la troisième génération.7 (VASAK, 1997, p. 1654).

Com sua assertiva, o ator reitera a característica de tutela substancial dos direitos, que se consolidam com a atuação de uma fraternidade humana, atuação que explicita, cada vez mais, os novos direitos adequados a cada ser humano na convivência social, ocorrendo um movimento de dilatação de sua abrangência (MENDES; BRANCO, 2018). Entretanto, como exposto anteriormente, a substancialidade dos direitos, primordialmente sociais, não pode ser cumprida com a estrutura impessoal do Estado somente. Desse modo, o autor continua sua compreensão afirmando que

ils sont nouveaux, car lês aspirations qu'ils expriment sont nouvelles sous l'angle des droits de l'homme, visant à faire pénétrer la dimension humaine dans des domains don't elle était jusqu'ici trop souvent absent, étant abandonnée à l'État, aux États: le développement, la paix, l'environnement, l'assistance humanitaire, le patrimoine commun de l'humanite..$^{8}$ (VASAK, 1997, p. 1654).

Essa novidade de diretos faz-se, fundamental, pois se distancia do indivíduo-cidadão como titular, destinando-se à proteção de grupos humanos presentes em povos e nações, possuindo titularidade transindividual ao exigirem participação em nível mundial para sua efetivação (SARLET, 2018, p. 320), ${ }^{9}$ além de englobar também aspectos econômicos, sociais e culturais (PEREZ LUÑO, 2003, p. 524).

É evidente que esses direitos surgem justamente no momento em que a economia mundial passa a assentar sua característica própria nas relações globais, afetando indubitavelmente as relações humanas e, como consequência, o meio ambiente cultural e natural. Exemplo fático disso provém da análise comparativa as constituições, percebendo-se uma nítida preocupação com as consequências dos atos humanos para com o meio ambiente. Em 1949, declara a Constituição da República Federal da Alemanha o poder regulador da União sobre a proteção da Natureza; a Suíça, em 1957, emenda

\footnotetext{
"Não têm, não deveriam ter", direitos humanos em segredo para uma fraternidade entre os homens e para sua indispensável solidariedade, direitos que deveriam os unir em um mundo acabado cujo tempo já tinha começado? Tal é o sentido de novos direitos humanos da terceira geração (tradução nossa).

8 São novos, já que as aspirações que expressam são novas abaixo do ângulo dos direitos humanos, visando a fazer penetrar a dimensão humana nos domínios que era até agora muitas vezes ausente, estando abandonada ao Estado, aos Estados: o desenvolvimento, a paz, o meio ambiente, assistência humanitária, o patrimônio comum entre a humanidade (tradução nossa).

9 Como afirma Morais (1996, p. 163-165), "não se trata mais de fazer frente ao arbítrio do Estado relativamente a determinados indivíduos, nem mesmo de demandar a solução/garantia de certas pretensões/benefícios a grupos determinados de pessoas. Trata-se, isto sim, de fomentar o caráter solidário do homem, fazendo-o compreender uma espécie de destino comum que o prende aos demais. A violação não se estabelece mais na relação do indivíduo com o Estado, sequer a pretensão se dirige a um Estado. Ambas refletem como que uma co-responsabilidade pela qualidade e continuidade da vida humana. A garantia ou a violação afetam a todos inexoravelmente."
} 
normas de proteção ambiental com sua antiga constituição. Além desses países temos exemplos como Bulgária (1971), Cuba (1976) e, em 1977, a União Soviética (SILVA, 2007, p. 43-44).

A preocupação com o ambiente, que, paulatinamente, possibilitará que também haja preocupação com o patrimônio cultural num geral, é a manifestação, dentre outros fatores, de uma nova concepção Estatal e da convivência do ser humano no mundo globalizado. Desse modo, essas novas preocupações transindividuais

han dejado asi de entender-se como Staatsschranken (limites de la acción estatal) caracterizados por uma función prioritária de defensa (Abwehrfunktion), para assumir el papel de autênticos Staatszwecke (fines de la acción estatal) a través de la garantia de la participación (Tailnahmefunktion) de los ciudadanos en las diversas esferas de la vida social, econômica y cultural. (PEREZ LUÑO, 2003, p. 524).

A partir de uma análise da filosofia do direito desse fenômeno supracitado, ratifica-se a tese de que as coletividades passam a concretizar os direitos necessários na sociedade conjuntamente com o Estado, a partir do conceito de fraternidade. Em Honneth (2015, p. 129-131), é possível proceder a reconstrução normativa da esfera jurídica a partir de duas perspectivas. A primeira se refere ao sistema do direito que garante aos indivíduos um espaço de autonomia privada, onde os sujeitos possam se resguardar de todos os deveres e vinculações para com os outros, e, possa reconhecer o sentido e a direção da condução individual de suas vidas (direitos de primeira e segunda geração). A segunda perspectiva é de uma autonomia coletiva, onde os sujeitos, cooperando em sociedade civil, deliberam sobre quais direitos devem ser concedidos e como devem ser implementados (direitos de terceira geração). O sistema jurídico, nessa segunda perspectiva, só pode surgir em relação a esferas institucionais da liberdade social, na chamada eticidade.

A soma dos direitos subjetivos, de primeira e segunda geração, permite que se compreenda o sujeito individual em sua coesão interna como resultado de um esforço para criar uma esfera protegida de intromissões externas. $\bigcirc$ que Honneth denomina como primeira geração de direitos subjetivos, ou, os direitos liberais de liberdade, significa normativamente permitir ao indivíduo adotar uma posição de autocomunicação puramente privada, protegida pelo Estado. Desse modo, os direitos liberais de liberdade remetem conceitualmente a uma complementaridade dos direitos sociais - segunda geração -, que garantem aos indivíduos a medida de segurança econômica e bem-estar material necessários para explorar seus próprios objetivos de vida de maneira privada e afastando-se das conexões de cooperação social.

Por outro lado, se as duas primeiras classes de direitos erguem uma barreira de proteção, por trás do qual o indivíduo pode se retirar, a terceira classe (direitos políticos) é construída para superar esse isolamento produzido. Assim, o conceito de direitos políticos remete a uma atividade que deve ser exercida em cooperação com todos os demais partícipes do direito. Portanto, as duas primeiras gerações de direitos só se realizam quando as pretensões por elas garantidas são aproveitadas para a 
construção de um eu privado, enquanto a terceira geração deve ser interpretada como um estímulo à cooperação e formação de uma vontade comum.

Desse modo, os direitos políticos geram uma espécie de liberdade individual, que não existe de modo puro e simples já na mera disposição sobre direitos subjetivos, mas está ligada ao grau de atividade com que os demais partícipes do direito defendem sua realização. Afinal, na categoria dos direitos políticos, a relação jurídica indica uma esfera social de liberdade cuja condição de existência é todo um conjunto de formas éticas de comportamento, não podendo ser descrita apenas através dos direitos subjetivos (HONNETH, 2015, p. 146).

Referente ao aspecto histórico e econômico, dentro das crises de produção industrial pela qual hoje se passa, o meio ambiente talvez seja um dos mais notórios direitos a serem respeitados. Como visto acima, com o passar dos tempos as Constituições foram catalogando esse direito como forma de oferecer dignidade às pessoas através de um ambiente saudável, seja ele natural, urbano ou laboral. São direitos, pois "que refletem as potencialidades construtivas e destrutivas, ao mesmo tempo, de nosso desenvolvimento." (MORAIS, 1996, p. 163-164).

A partir das mudanças econômicas supracitadas, a responsabilidade constitucionalinternacional apresenta defesa "a la persona de lo que ha sido denominado el 'Leviathan económico', esto es, de la dominación ciega del mundo natural y humano por el imperio de leyes económicas que producen la alienación de la persona y pueden conducir a una catástrofe planetária." (PEREZ LUÑO, 2003, p. 487-488).

Note-se que, tendo como base a tutela ambiental, a característica de complementaridade das gerações de direitos é nitidamente efetuada. Ou seja, quando se protegem direitos transindividuais não se está a proteger somente uma geração, mas nela estão implícitos muitos outros direitos. Não é coincidência que, subjacente à preocupação da dignidade humana e de seus direitos fundamentais está a preocupação ambiental com o desenvolvimento integral e sustentável. Nesse sentido, faz-se necessário a inclusão ademais dos aspectos liberais e sociais, da variável ecológica, na manifestação do intrínseco valor à natureza no que tange o relacionamento humano (SARLET; FENSTERSEIFER, 2013, p. 43).

Assim como o meio ambiente, a paz é uma forma da busca desses direitos dos povos. Senese (1990, p. 199) é radical em sua afirmação de que "le maintien de la paix et la promotion de la justice deviennent ainsi le principe d'une nouvelle légitimité des États, dans l'ordre interne aussi bien que dans l'ordre international."10 E continua o autor, afirmando que o Estado não possui o poder soberano ilimitado a ponto de agir com a supressão da paz, sendo essa, hoje, uma necessidade primária e concreta de homens e mulheres, tornando-se uma obrigação estatal garanti-la e, mais do que isso, tornou-se obrigação do estado permitir que ela seja garantida pelos seus cidadãos (SENESE, 1990, p. 201). Afinal, na promoção da guerra e da violência, não há distinção entre o público e o privado, mas é frequentemente a vida do inocente que está em jogo. De certo modo, aqui se apresenta muito

\footnotetext{
10 A manutenção da paz e a promoção da justiça chegam a ser assim o princípio de uma nova legitimidade dos Estados, numa ordem interna bem como na ordem internacional (tradução nossa).
} 
enfaticamente, o direito de autodeterminação dos povos. Ou seja, o ente estatal, com toda a sua estrutura, necessita permitir que homens e mulheres possam viver pacificamente. Num mundo em que há cada vez mais brigas por territórios e meios naturais, esses direitos precisam trazer uma mínima reflexão. ${ }^{11}$

É evidente, pois, que a proteção desses direitos transindividuais, de caráter nitidamente internacional, por mais que necessitem ainda de maior viabilidade constitucional, tornaram-se, por muitos países, aceitos como um direito fundamental, não somente no sentido de um catálogo formal, como o disposto no art. $5^{\circ}$ de nossa Constituição Federal, mas como descoberta e formulação de novos direitos que "são e serão sempre um processo sem fim, de tal modo que quando 'um sistema de direitos se faz conhecido e reconhecido, abrem-se novas regiões da liberdade que devem ser exploradas'." (BONAVIDES, 2014, p. 584).

Essa liberdade que possibilita a maior fraternidade humana através da paz, do meio ambiente e o cuidado para com o patrimônio histórico e cultural da humanidade, insere o consumo enquanto tal e os próprios consumidores globais como participantes efetivos desses direitos transindividuais, como afirma Perez Luño (2003, p. 527), a partir da concepção artística e cultural que

también la defensa de los consumidores prevista por la Constitución [española] en su artículo 51 puede ser e marco que propicie uma ación de los poderes públicos tendente a imponer uma nueva lógica en la dimensión de la obra artística como objeto de consumo. Se trata de establecer mecanismos de defensa para el goce, o, si se quiere, em el consumo de bienes artísticos y culturales que impidan cualquier fenômeno de adulteración o especulación manipuladora de estas produciones.

A participação da atividade consumerista nesses direitos pode se dar como forma a promovê-los ou suprimi-los. Assim sendo, a partir do que fora escrito sobre os Direitos Fundamentais referentes à Terceira Geração, trabalhar-se-á como o consumo se insere nessa nova concepção de direitos fraternos e solidários e a preocupação com o meio ambiente.

\section{Consumo como supressão}

A ação humana de consumir algo, seja para fins de satisfação das necessidades básicas ou supérfluas, é uma atividade presente em toda e qualquer sociedade humana (BARBOSA, 2008, p. 7). Contudo, apenas a sociedade contemporânea é uma sociedade de consumo. $\bigcirc$ termo sociedade de consumo, como aponta Barbosa, remete para uma determinada dimensão, percebida como

\footnotetext{
$\overline{11}$ Não se pode esquecer que a defesa da paz, no Brasil, mostra-se como uma construção literária e doutrinária, não estando previsto, por exemplo, como Direito Fundamental, mas como princípio norteador das relações internacionais. Diferente da Constituição Espanhola que alude expressamente "a la paz em três momentos muy diferentes de su texto: $1^{\circ}$ ) Em el Preámbulo al proclamar como uno de los propósitos básicos de la Nación española su voluntad de 'Colaborar em el fortalecimiento de unas relaciones pacíficas y de eficaz cooperación entre todos los pueblos de la Tierra. $2^{\circ}$ ) Em su parte dogmática, donde precisamente inicia su Título I cifrando em la dignidad de la persona, em sus derechos inherentes y em el libre desarollo de su personalidad el 'fundamento de orden político y de la paz social." (PEREZ LUÑO, 2003, p. 536).
} 
específica, e definidora das sociedades contemporâneas (BARBOSA, 2008, p. 25). Tal rótulo não busca descrever a sociedade em si, mas é usado como uma maneira de tentar explicar as práticas reais do consumo atual e a paixão aparentemente crescente por coisas materiais (JOHANSSON, 2014, p. 15). A expressão "sociedade de consumo" aparece, segundo Lipovetsky pela primeira vez na década de 20, popularizando-se nas décadas de 50 e 60, e possuindo grande relevância absoluta na contemporaneidade, como demonstra seu amplo uso na linguagem popular, nos discursos políticos e na produção científica (LIPOVETSKY, 2007, p. 23).

O consumo é a uma modalidade característica da civilização industrial, sendo um processo de satisfação das necessidades. $\bigcirc$ consumo não é apenas o modo passivo de apropriação que se opõe ao modo ativo de produção. Para além disso, o consumo é um modo de relação, com os objetos e com a coletividade, um modo de atividade sistemática e de resposta global no qual se funda todo sistema cultural (BAUDRILLARD, 2009, p. 205-206).

Para Lipovetsky, na atual fase de consumo, o consumo pode ser caracterizado como um "ato social", um empoderamento ou um aumento de autoestima. Ressalta-se que nas relações de consumo atual não existe horário definido para que estas aconteçam, assim como elas podem ocorrer por intermédios eletrônicos. Na sociedade atual, é possível dizer que o individualismo se sobrepõe ao coletivo e traz consigo uma "nova relação emocional dos indivíduos com as mercadorias, instituindo o primado do que se sente, a mudança da significação social e individual do universo consumidor que acompanha o impulso de individualização de nossas sociedades." (LIPOVETSKY, 2007, p. 46).

A visão idealista dessa modernidade hiperconsumista é de que crescimento é abundância e a abundância é a democracia (BAUDRILLARD, 2011, p. 52). Como é a empresa de produção que controla os comportamentos de mercado, dirigindo e configurando as atitudes e as necessidades dos consumidores, é possível falar, ao menos em uma tendência à ditadura total da ordem de produção (BAUDRILLARD, 2011, p. 82). O sistema precisa dos homens como trabalhadores (trabalho assalariado), como economizadores (impostos, empréstimos) e, cada vez mais, como consumidores (BAUDRILLARD, 2011, p. 99). Assim, consumir se torna um elemento de dominação social (através da atomização dos indivíduos consumidores). Contudo, ao mesmo tempo ele aponta para a necessidade de coação burocrática cada vez mais forte sobre os processos de consumo (BAUDRILLARD, 2011, p. 100).

Ao mesmo tempo em que inúmeras tecnologias possuem a capacidade de aproximar os sujeitos, mais cresce o sentimento de solidão. Cada um está sozinho e ao mesmo tempo globalmente conectado em sua tela. É pertinente notar que esse paradoxo do cuidado e do esquecimento; da preocupação coletiva e de um completo individualismo, está consubstanciado no ideal de liberdade de escolha no consumo que perpassa as relações sociais. $\bigcirc$ novo processo de consumo, não transformou o homem em um ser emancipado como se esperava, mas serviu apenas para tornar mais difícil aos sujeitos se relacionarem de forma intensa entre si. Por onde se olha na sociedade hiperconsumista existe solidão, vazio e depressão (GONÇALVES, 2012, p. 21-22). 
O consumo desenfreado e ostentativo dos bens materiais enfraquece e desagrega a comunidade, os sujeitos se esquecem de reforçar a busca e a prática dos bens relacionais, amizade, amor, família, etc. (GONÇALVES, 2012, p. 34). Debord (1997, p. 28) afirma que o mundo que o espetáculo apresenta é o mundo da mercadoria dominando tudo o que é vivido, este mundo da mercadoria se movimenta pelo consumo e pelo afastamento dos homens entre si e em relação a tudo que produzem. Baudrillard (2009, p. 161), nesse ponto se pergunta se é possível falar em alienação

No seu conjunto, o sistema da personalização dirigida é vivido pela imensa maioria dos consumidores como liberdade. É somente para o olhar crítico que esta liberdade pode aparecer como formal, e a personalização no fundo como uma desventura do indivíduo. Mesmo neste caso em que a publicidade joga com a motivação vazia (marcas duplicadas para um mesmo produto, diferenças ilusórias, condicionamento variável etc.), em que a escolha acha-se antecipadamente presa na armadilha, é preciso admitir que mesmo as diferenças superficiais são reais a partir do momento em que são valorizadas como tal.

Uma conclusão possível desta linha é que o fim último de uma sociedade de consumo é a funcionalização do consumidor, a monopolização psicológica de todas as necessidades, a unanimidade do consumo que corresponde enfim harmoniosamente à concentração e ao dirigismo absoluto da produção (BAUDRILLARD, 2009, p. 193). Em outras palavras, essa sociedade consumocentrista ${ }^{12}$ gera um processo permanente de renovação formal dos produtos e das necessidades, tal processo objetiva provocar uma dinâmica favorável ao crescimento ininterrupto do mercado. No consumocentrismo, para além de uma sociedade de homens competindo pelo seu lugar no mercado, se percebe um desvalorizar do outro, no consumir os sujeitos são pacificados e tem suas necessidades neutralizadas. Este é um narcisismo consumocentrista que afasta e individualiza os sujeitos, reduzindo a relevância das normas sociais e aumentando das leis econômicas.

Na tradição liberal, a soberania do consumidor possui dois significados: (1) a possibilidade de o indivíduo definir suas necessidades, desejos e vontades: é o poder de se autodeterminar; (2)

12 O consumo se torna o centro da sociedade, onde tudo acaba girando em torno do mesmo. Para Pereira, Calgaro e Pereira (2016, p. 267): "onde a ideia que surge no deslocamento do enfoque direcionado sobre o consumidor para concentrá-lo, especificamente, sobre o consumo. Neste viés, entende-se que se ultrapassou a denominada sociedade hiperconsumista, dando azo a uma sociedade consumocentrista. Nesse enfoque o consumo passa a ser o elemento principal das atividades humanas, deslocando o "ser" para o "ter" e posteriormente para o "aparentar". Desta forma, o consumo se torna o centro da sociedade contemporânea, onde o consumidor vai buscar todas as possibilidades de sua nova razão de viver. Consumir é existir". Assim sendo, "A sociedade vivenciou uma série de teorias ao longo do tempo, o que faz com que as condutas humanas fossem dirigidas por certas teorias/doutrinas/ideias/ideologias, que levavam a mudanças sociais e individuais. Pode-se destacar, de modo exemplificativo, dentro do contexto que se está abordando, o cosmocentrismo (o cosmos é o centro de tudo); o teocentrismo (Deus se torna o centro); o antropocentrismo (tudo gira em torno do homem). Na sociedade moderna contemporânea que já está sendo denominada de pós-moderna, conforme se pretende demonstrar aqui, se insere o consumocentrismo, como elemento dominante para onde se dirigem o pensamento e as atividades do cidadão moderno, fazendo com que o mesmo seja levado a consumir, pois, através desse ato, ele se realiza como ser individual e social, pois que ele somente é se consumir." (PEREIRA; CALGARO; PEREIRA, 2016, p. 267). E, continuam afirmando que "Nesse cenário, na sociedade moderna consumocentrista, entende-se que o consumo se coloca no centro de todas as decisões que envolvem o indivíduo, pois o mesmo perde sua identidade como ser que participa das decisões sociais para se transformar (apenas) em consumidor heteronomamente guiado. Assim, a noção de consumocentrismo, na forma que se apresenta para o presente trabalho, demonstra a influência do mercado nas tomadas de decisão que envolvem o consumo e os aspectos socioambientais." (PEREIRA; CALGARO; PEREIRA, 2016, p. 267). 
a possibilidade de impor aos produtores o que devem produzir para satisfazer os consumidores, determinado os rumos do mercado. A soberania do consumidor vai sendo diminuída à medida que fatores externos, não contidos pelos direitos individuais, mínima liberdade. É nesse sentido que o consumidor tem sua soberania mitigada e passa a ser reconhecido como vulnerável e hipossuficiente (BIERWAGEN, 2001, p. 83).

Uma das consequências da ideologização do consumidor é a transferência da solução de problemas coletivos para a esfera individual, processo que desemboca, entre outros fenômenos, na formação do consumidor consciente. Ao levar os interesses de natureza difusa e de caráter indivisível para o âmbito privado, a resolução dos problemas se mostra problemática e pouco eficaz, já que os resultados dependem de ações individuais. A privatização dos problemas coletivos, também é responsável pelo enfraquecimento do diálogo das esferas pública e privada, dos sentimentos de pertencimento, solidariedade e de comunidade. Ela exclui do debate público os problemas, já que a solução estaria implícita na prática do consumo consciente, e, assim, manteria a participação dos consumidores subordinada ao que o mercado disponibilizasse (BIERWAGEN, 2001, p. 86-87).

Nessa perspectiva, percebe-se as contrariedades que a sociedade de consumo pode apresentar quando relacionados direitos de terceira geração. Como visto, na primeira parte desse trabalho foi apresentada a ideia de que poderia o consumo ser um viabilizador destes direitos, o que se apresenta a partir da análise realizada nesta seção é de que não ocorre uma globalização do direito ao consumo, mas uma globalização da proteção de consumidores atomizados. Além disso, estes consumidores atomizados reforçam esta concepção, pois percebem a solidariedade e a fraternidade humana a partir de sua capacidade individual e privada de adquirir bens e serviços, produzindo não uma relação pessoa-pessoa, mas pessoa-objeto.

Honneth (2015) entende que o consumo compreendido dentro dos direitos de primeira e segunda geração propicia ao indivíduo utilizar apenas autonomia privada, ou seja, dispor de um espaço de proteção aceito universalmente e exigível individualmente, que lhe permite se retirar de seus deveres e laços sociais. Assim, o núcleo do consumo é constituído de uma esfera de privacidade individual. Dessa forma, é evidente que o consumo nessa perspectiva não se apresenta como uma esfera ou lugar de autorrealização individual. O problema identificado é de que o emprego do direito meramente subjetivo cria uma forma de estado de exceção temporário, no qual aquilo que é tratado efetivamente na conformação de uma vida autônoma é de certo modo suspenso. Nesse estado, o sujeito jurídico não reflete sobre os objetivos individuais, nem os realiza de maneira ética, porque trata seus parceiros de interação apenas como atores com interesses estratégicos (HONNETH, 2015, p. 155-156). Como consequência, no que se refere a relação entre direitos fundamentais aqui tratados e o consumo, nota-se o paradoxo no qual a liberdade de consumo não se reflete, ipso facto, numa maior liberdade de organização social e cuidado humano na globalização sem fronteira. Antes, infelizmente, na análise supracitada, nota-se que o aspecto intimista do consumo acaba por criar 
uma despreocupação social, onde a garantia da capacidade de consumir torna-se a concretização consequencial de direitos coletivos.

É importante lembrar que, ainda que o consumidor adote um comportamento de revolta, este novo anticonsumidor não faz mais do que representar uma das tendências do individualismo contemporâneo, marcado pela suspeita em relação às instituições, a reflexividade dos comportamentos individuais e as buscas qualitativas. Uma vertente da sociedade de hiperconsumo incita ao frenesi do "sempre mais, sempre novo"; uma outra, baseada na informação, na dinâmica da autonomia subjetiva, nas aspirações de qualidade de vida e de identidade pessoal, leva os indivíduos a recusar um consumismo sem consciência, formatado e "sob influência". Privilegiando a qualidade de vida, desejosos de escapar ao condicionamento publicitário, preocupados em exercer um controle sobre sua vida cotidiana emancipando-se do conformismo de massa, os "anticonsumidores" não se opões à sociedade de hiperconsumo: são uma de suas manifestações exemplares, sem dúvida destinada a ampliar-se. Esse movimento não constitui de modo algum um esboço de saída da fase III: acentuando a individualização das despesas, diversificando e fragmentando os modos de consumo, obrigando os industriais a abrir mais ainda sua política de segmentação dos mercados, o anticonsumismo não faz senão consumar a essência da sociedade de hiperconsumo (LIPOVETSKY, 2007, p. 344-345). Portanto, sendo o consumo algo presente em nossa sociedade atual e a simples crítica a ele partir de uma simples matriz comum, necessita-se perceber nele aspectos que possibilitam a concretização de direitos para potencializá-los na sociedade hodierna.

\section{Consumo como realização: a geração de direitos e o meio ambiente}

O consumo, por si só, pode levar a um individualismo possibilitado pelo gozo que o adquirir e possuir trazem aos cidadãos. Entretanto a busca por uma capacidade de consumo consciente e responsável pode ser, hoje, uma dá principais manifestações de responsabilidade social do cidadão. O consumidor deve ser incentivado a fazer com que o seu ato de consumo seja também um ato de cidadania. Essa mudança de comportamento é um processo que requer sensibilização e mobilização social, onde a informação é fundamental. Assim, para que haja maior conscientização, é necessário que o consumidor tenha acesso à informação referente às atividades corporativas, para que possa exercer melhor o seu poder de escolha, e preferir as empresas socialmente responsáveis e comprometidas com a preservação do meio ambiente. (PEREIRA; CALGARO, 2016, p. 33-51, 47).

Ou seja, ipso facto, o consumo não dilacera com direitos, mais especificamente, os fundamentais de terceira geração. Portanto não é num "tudo ou nada" de um maniqueísmo social que se pode pensar o ato de consumir. Afinal, quando se reconhece que ao consumir também se pensa, se escolhe e reelabora o sentido social, é preciso se analisar como esta área de apropriação de bens e signos intervém em formas mais ativas de participação do que aquelas que habitualmente recebem o rótulo de consumo. Em outros termos, deve-se perguntar se ao consumir não se está 
fazendo algo que sustenta, nutre e até certo ponto, constitui uma nova maneira de ser cidadãos (CANCLINI, 2006, p. 42). Logo, deve-se admitir que no consumo se constrói parte da racionalidade integrativa e comunicativa de uma sociedade (CANCLINI, 2006, p. 63). Desse modo,

\begin{abstract}
a proteção ao consumidor guarda, ainda, estreita relação com a dignidade da pessoa humana, não só porque esta proteção estende-se à proteção da vida, da saúde e da liberdade do consumidor, mas, principalmente, porque o consumo é o acesso primário ao mínimo existencial em uma sociedade capitalista justa e solidária. [Além disso] a participação do indivíduo no mercado, como consumidor, é, portanto, uma forma de inclusão social, desde que não participe apenas como uma engrenagem do sistema, mas possa exercer efetivamente sua liberdade. É o direito que consagra o ato de consumir como uma forma de participação ativa do indivíduo na economia, e, por conseguinte, na vida da sociedade. (DORINI, 2010, p. 47-48).
\end{abstract}

Entretanto, para que se possa articular o consumo com um exercício refletido da cidadania, é necessário que se reúnam ao menos estes requisitos: a) uma oferta vasta e diversificada de bens e mensagens representativos da variedade internacional dos mercados, de acesso fácil e equitativo para as maiorias; b) informação multidirecional e confiável a respeito da qualidade dos produtos, cujo controle seja efetivamente exercido por parte dos consumidores, capazes de refutar as pretensões e seduções da publicidade; c) participação democrática dos principais setores da sociedade civil nas decisões de ordem material, simbólica, jurídica e política em que se organizam os consumos: desde o controle de qualidade dos alimentos até as concessões de estações de rádio e anais de televisão, desde o julgamento dos especuladores que escondem produtos de primeira necessidade até os que administram informações estratégicas para a tomada de decisões (CANCLINI, 2006, p. 70).

Mesmo que a ideia de monetarização das relações, atribuindo-se valores às relações vividas, num Estado democrático

o consumidor-cidadão não se limita a ser o receptor passivo de produtos ofertados no mercado [...]. Não lhe interessa somente o que é produzido, mas como se produz. Ele quer influir no processo produtivo, para que este esteja em conformidade com os valores cívico-políticos que professa: de acordo com regras que vedam o trabalho infantil, respeito aos direitos fundamentais dos trabalhadores, preservação do meio ambiente e do modo de vida das comunidades tradicionais, etc. (BARZOTTO; BARZOTTO, 2014, p. 14).

Os Direitos Fundamentais de terceira geração, pois, antes de serem naturalmente suprimidos pela prática consumerista, podem ser, de certo modo, efetivados através da cidadania presente no consumo, possibilitando uma base integrativa entre a sociedade. Pode até ser que o consumo provoque e traga à tona todo um aspecto egocêntrico nas relações sociais, mas não se pode negar que, muitas vezes, a busca pela paz e pelo meio ambiente cultural e natural sadio, são buscados a partir de uma cidadania encontrada no consumo, cidadania que, caso fosse estritamente dependente de participação pública tradicional, estaria, possivelmente, muito enfraquecida. 
Com o observado acima o consumo acaba propiciando a degradação do meio ambiente gerando problemas socioambientais. $\bigcirc$ mercado acaba criando artifícios e produtos que vem a trazer a degradação através de resíduos que são descartados no meio ambiente, por exemplo. Deste modo, o consumocentrismo leva a problemas ambientais e também sociais que necessitam serem sanados. Com os direitos de terceira geração o meio ambiente e o consumo, que são direitos difusos, são categorizados como protegidos pela Constituição Federal de 1988, com isso as leis infraconstitucionais e as políticas públicas podem minimizar esses impactos. Como afirma o autor Marcelo Abelha (2004, p. 43):

O interesse difuso é assim entendido porque, objetivamente estrutura-se como interesse pertencente a todos e a cada um dos componentes da pluralidade indeterminada de que se trate. Não é um simples interesse individual, reconhecedor de uma esfera pessoal e própria, exclusiva de domínio. O interesse difuso é o interesse de todos e de cada um ou, por outras palavras, é o interesse que cada indivíduo possui pelo fato de pertencer à pluralidade de sujeitos a que se refere à norma em questão.

Com essa tutela de direitos entende-se que há uma viabilidade para se consagrar a solidariedade e a proteção tanto da natureza como do meio ambiente na sociedade moderna. A terceira geração de direitos fundamentais que é destinada a proteção da humanidade, sendo preocupada com o meio ambiente, no viés de conservação e de proteção, além da proteção do consumidor e do desenvolvimento econômico. Com isso essa geração de direitos contribui para a consciência jurídica.

A partir da consciência jurídica permite que se busque assegurar a todos uma existência digna, livre e igual, objetivo alicerçado na CF/88, no art. 3, I. Deste modo, é importante que se vislumbre a efetividade dos direitos de solidariedade e fraternidade no intuito de proteção dos consumidores e do meio ambiente. As corporações e as empresas devem buscar objetivos que visem a um consumo consciente e sustentável, onde tanto o meio ambiente como a sociedade sejam respeitados e, não sejam induzidos a "endeusar" os modos de consumo, a ponto de serem adestrados ao consumocentrismo.

Assim, a preocupação com o meio ambiente e o consumidor como afirma Bobbio (1992, p. 6) "o mais importante deles é o reivindicado pelos movimentos ecológicos, o direito a viver em meio ambiente não poluído." Desta maneira, o direito de terceira geração permite a vida no planeta e a busca da solidariedade social, onde pessoas razoáveis e racionais convivem de forma a cooperar na busca de uma sociedade onde o consumo não seja o centro dela e não venha a gerar problemas socioambientais. Conclui-se que o respeito a esses direitos de terceira geração levam a emancipação dos cidadãos e a sua dignidade vem a ser respeitada, com isso se atinge os preceitos para uma futura cidadania plena. 


\section{Considerações Finais}

No trabalho se falou dos direitos de terceira geração e seus preceitos de solidariedade e fraternidade aplicados ao consumo e ao meio ambiente. Com isso, se observa que essa geração de direitos é contínua e constante buscando ideias que visem o bem-estar, a liberdade e a dignidade das pessoas, tendo como fundamento a ampliação de medidas necessárias para proteger o ser humano contra as agressões de seus direitos, mas também protegendo o meio ambiente e os consumidores, por exemplo.

Tanto o direito do consumidor como o direito ao meio ambiente são direitos que devem ser protegidos nas sociedades industrializadas, onde a produção e o consumo, se inserem de forma complexa nos meios de distribuição e comércio. As relações consumeristas são imediatas e geram contradições sociais e ambientais, as quais devem ser minimizadas. A industrialização e a globalização atingem o ápice na atualidade, onde se tem acesso a todos os tipos de produtos que podem ser adquiridos em qualquer local e a qualquer momento, contudo é importante salientar que nem todos os cidadãos tem acesso a esses bens, pois os países em desenvolvimento passam por uma premente desigualdade social, onde os direitos fundamentais de terceira geração devem ser almejados de forma mais ampla e plena.

Esses direitos que surgiram num momento em que a economia e as relações globais afetavam as relações humanas, incluindo o meio ambiente, são uma possibilidade para se retomar no mundo globalizado, como alternativa de eficácia e efetivação de direitos aos cidadãos. Esses Direitos Fundamentais de terceira geração, antes de serem naturalmente suprimidos pela prática consumocentrista - prática esta que se volta apenas para os direitos de primeira e segunda geração -, podem ser, de certa forma, efetivados através da cidadania presente no consumo, suprassumindo os direitos de primeira e segunda geração que agora se tornam presentes e, em determinados aspectos, são sustentados por meio dos direitos de fraternidade e solidariedade.

Como se observou acima, percebe-se os paradoxos na sociedade de consumo quando se relaciona com os direitos de fraternidade e solidariedade, pois há necessidade de articular métodos de que visem o exercício da cidadania e o respeito ao meio ambiente. A participação democrática da sociedade civil e de todos os seus setores; a retomada da confiança do consumidor, com informações e publicidades que tenham veracidade e transparência; a busca de uma sociedade pautada no respeito das pessoas, ou seja, de seus cidadãos, podem ser algumas alternativas a serem analisadas.

Os direitos fundamentais de terceira geração não devem ser suprimidos na sociedade consumocentrista, mas devem ser efetivados através da cidadania que pode estar presente no consumo. O Estado através da Constituição Federal, como é o caso do Brasil, tem o dever de garantir a busca da efetivação desses direitos de solidariedade e fraternidade, onde hajam alternativas para que se crie uma sociedade onde o poder econômico não prevaleça sobre esses direitos. Não se é contra o crescimento econômico, mas sim contra o abuso desse crescimento que leve a meios inidôneos de consumo e que afaste a ruptura de direitos fundamentais que são básicos a todos os seres humanos. 
Importante denotar que uma vez que foram estabelecidas normas que garantam a eficácia e a aplicabilidade desses direitos fundamentais, o Estado não pode e não deve retroceder e nem os reduzir, tampouco revogar ou extinguir tais direitos. Assim sendo, o Estado tem o dever e está vinculado a tarefa de melhorar, distribuir e redistribuir os recursos para todas as pessoas que deles necessitaram, pois é dessa maneira que se garante os direitos fundamentais de solidariedade e fraternidade. E, com isso, efetiva-se a proteção do consumidor e do meio ambiente numa sociedade fraterna e solidária.

\section{Referências}

ABELHA, Marcelo. Ação Civil Pública e Meio Ambiente. 2. ed. Rio de Janeiro: Forense Universitária, 2004.

BARBOSA, Lívia. Sociedade de consumo. 2. ed. Rio de Janeiro: Jorge Zahar Editora, 2008.

BARZOTTO, Luciane Cardoso; BARZOTTO, Luis Fernando. Mercado, Fraternidade e o Consumidor-cidadão. Revista de Direito do consumidor, v. 94, jul./ago. 2014. Disponível em: file://C:/Users/ ADMIN/Downloads/Mercado,\%20fraternidade\%20e\%20॰\%20consumidor-cidad\%C3\%A3o.pdf. Acesso em: 8 maio 2018.

BAUDRILLARD, Jean. O sistema dos objetos. 5. ed. São Paulo: Perspectiva, 2009.

BIERWAGEN, Mônica Yoshizato. A ideologização do consumo consciente: uma análise sobre soberania do consumidor e liberdade de escolha. 2011. Dissertação (Mestrado em Ciência Ambiental) - Programa de Pós-Graduação em Ciência Ambiental, Universidade de São Paulo, São Paulo, 2011.

BOBBIO, Norberto. A era dos Direitos. Tradução: Carlos Nelson Coutinho. Rio de Janeiro: Campus, 1992.

BONAVIDES, Paulo. Curso de Direito Constitucional. 29. ed. São Paulo: Malheiros, 2014.

CANCLINI, Néstor García. Consumidores e cidadãos: conflitos multiculturais da globalização. 6. ed. Rio de Janeiro: Editora UFRJ, 2006.

CANOTILHO, José Joaquim Gomes. Direito constitucional e teoria da constituição. 2. ed. Portugal: Almedina, 1998.

DEBORD, Guy. A sociedade do espetáculo. Rio de Janeiro: Contraponto, 1997.

DORINI, João Paulo de Campos. Direito de acesso ao consumo. Revista de Direito do Consumidor, v. 75, p. 43-79, jul./set. 2010.

GILISSEN, John. Introdução histórica ao direito. 4. ed. Lisboa, Portugal: Fundação Calouste Gulbenkian, 2003.

GONÇALVES, Marco Antonio. Ética e consumo: uma análise dos hábitos de consumo. 2012. Dissertação (Mestrado em Filosofia) - Programa de Pós-Graduação em Filosofia, Universidade de Caxias do Sul, Caxias do Sul, 2012. 
HONNETH, Axel. O Direito da Liberdade. Tradução: Saulo Krieger. São Paulo: Martins Fontes, 2015.

JOHANSSON, Pernilla. Consuming the city: how does non-consumers experience the city? 2014. Dissertação (Mestrado em Estratégias Ambientais) - Department of Sustainable Development, Environmental Science and Engineering, School of Architecture and the Built Environment. Disponível em: http://urn.kb.se/resolve?urn=urn:nbn:se:kth:diva-147194. Acesso em: 16 jan. 2018.

LAQUIÈZE, Alain. État de droit e soberania nacional na França. In: COSTA, Pietro; ZOLO, Danilo; SANTORO, Emilio (org.). O estado de direito: história, teoria, crítica. São Paulo: M. Fontes, 2006.

LIPOVETSKY, Gilles. A felicidade paradoxal: ensaio sobre a sociedade de hiperconsumo. São Paulo: Companhia das Letras, 2007.

MENDES, Gilmar; BRANCO, Paulo Gustavo Gonet. Curso de Direito Constitucional. 13. ed. São Paulo: Saraiva, 2018.

MORAIS, Jose Luis Bolzan de. Do direito social aos interesses transidividuais: o Estado e o direito na ordem contemporânea. Porto Alegre: Livraria do Advogado, 1996.

PEREIRA, Agostinho Oli Koppe; CALGARO, Cleide; PEREIRA, Henrique Mioranza Koppe. Consumocentrismo e os seus reflexos socioambientais na sociedade contemporânea. Revista Direito Ambiental e Sociedade, v. 6, p. 264-279, 2016.

PÉREZ LUÑO, Antonio Enrique. Derechos humanos, estado de derecho y constitucion. 8. ed. Madrid: Tecnos, 2003.

SARLET, Ingo Wolfgang. A eficácia dos direitos fundamentais. 6. ed. rev., atual. e ampl. Porto Alegre: Livraria do Advogado, 2006.

SARLET, Ingo Wolfgang; FENSTERSEIFER, Tiago. Direito constitucional ambiental: constituição, direitos fundamentais e proteção do ambiente. 3. ed. São Paulo: Revista dos Tribunais, 2013.

SARLET, Ingo Wolfgang. Teoria geral dos direitos fundamentais. In: SARLET, Ingo Wolfgang; MARINONI, Luiz Guilherme; MITIDIERO, Daniel Francisco. Curso de direito constitucional. 7. ed., rev. atual. e ampl. São Paulo: Saraiva Educação, 2018.

SCHMITT, Carl. Théorie de la Constitution. Berlin: Presses Universitaires de France, 1993.

SENESE, Salvatore. Une "Troisième Génération" des droits de l'homme. In: BRAIBANT, Guy; MARCOU, Gérard. Les droits de l'homme: universalité et renouveau. Paris, França: L'Harmattan, 1990.

SILVA, José Afonso da. Curso de Direito Constitucional Positivo. 37. ed. São Paulo: Malheiros, 2014.

SILVA, José Afonso da. Direito ambiental constitucional. 6. ed. atual. São Paulo: Malheiros, 2007.

VASAK, Karel. Revisiter la troisième génération des droits de l'homme avant leur codifiation. In: VITA, Juan Alvarez et al (org.). Héctor Gros Espiell amicorum liber: persona humana y derecho internacional. Bruxelles: Bruylant, 1997. v. 2. 
